\title{
Letter of the president
}

RBCCV 44205-824

\section{José Teles de Mendonça*}

\section{Dear Colleagues,}

In our last meeting in Salvador, Brazil, during the $33^{\text {rd }}$ Congress of the Brazilian Society of Cardiovascular Surgery, we had the honor and privilege of being trusted with the leadership of the BSCVS over the next two years.

I would initially like to congratulate the organizers of the event commanded by the eminent president, Dr. Alexandre Brick, scientific director, Prof. Enio Buffolo and coordinator of the local organizing commission, Dr. Ricardo Eloy. They organized a magnificent congress where a harmonic interaction of very high quality scientific sessions prevailed with very relaxed and friendly meetings of this great family of surgeons, highlighting through science and love, the strength of Brazilian heart surgery.

The absence of our great colleague and friend, Dr. José Carlos Andrade was noted; he was not there in person but in spirit. His absence was due to treatment of a disease. We believe that he will beat this illness with his inner strength, with the encouragement of the prayers of his friends and through the will of God. We are all thinking of you, dear friend.

I would like to take this opportunity to thank colleagues of this society for their never-ending support and especially for the messages of kindness, solidarity and trust continuously expressed and endorsed at this moment, by granting us such a great honor.

I would also like to thank our colleagues, in particular members of the directorate who, by reserving time in their busy schedules, accepted the responsibilities and of course commitment to think and act for the Brazilian Society of Cardiovascular Surgery.

The aim of a society is to bring people together and to strengthen ideas that, when put into practice, can respond to the anxieties of the majority of the members and thus make the society strong. Hence, besides the directorate's normal responsibilities, new commissions have been created so as to increase the participation of members, to make the society more aware of the situation in Brazil and, with this, to elaborate and implant a more just and efficient program to fulfill its role.

The names and addresses of the members of the directorate, editors (Journal and Site), regional branch presidents, department and commission coordinators, as well as the secretariat of the society itself can be found in our site (www.sbccv.org.br).

The objectives of the society are divided into four groups:

1) Participative administration: an objective made much easier by previous administrations that includes regional representatives in the meetings of the directorate. Today, apart from the presidents, the departments and commissions also participate, thereby involving all segments in the planning of the coordinated program for the general organization of the society;

2) Financial structuring: To have a budget defined in the program and to follow the established plan of action. For this Dr. Roso, who was reelected treasurer after his brilliant work in the previous administration, has already started working. We need, however, to implement the recommended measures.

3) Strengthening the society: in every way from facilitating the spread of knowledge and fighting for better working conditions, to public recognition of its social importance. And finally.

4) To get closer to the members of the society: by offering to all, a series of services that justify the necessity of and faith in an institution that was established to serve them.

Let’s move forward! Participate!

Regards.

\section{* President of the BSCVS}

